\title{
Effect of yogurt containing deep sea water on health-related serum parameters and intestinal microbiota in mice
}

\author{
Sun Moon Kang, ${ }^{*}$ Jin Woo Jhoo, $†$ Jae In Pak, $\dagger$ III Kyoung Kwon, $†$ Sung Ki Lee, $†$ and Gur Yoo Kim ${ }^{1}$ \\ ${ }^{*}$ Animal Products Utilization Division, National Institute of Animal Science, Rural Development Administration, 1500 Kongjwipatjwi-ro, Iseo-myeon, \\ Wanju-gun 565-851, Korea \\ †Division of Applied Animal Science, College of Animal Life Sciences, Kangwon National University, KNU Ave 1, Chuncheon 200-701, Korea
}

\begin{abstract}
Deep sea water (DSW) has health benefits and is widely used as food supplement; however, its effect in fermented products has not been explored. Here, we investigated the effect of DSW-containing yogurt on health-related serum parameters and intestinal microbiota in mice. Animals were assigned to 3 feeding groups, which received water (control), normal yogurt (N-yogurt), or DSW-containing yogurt (DSW-yogurt) with a basal diet. Mice were killed at wk 4 or 8 of feeding and analyzed for serum parameters and microbial population in the small intestine. Both yogurt groups demonstrated increased populations of intestinal lactic acid bacteria compared with the control group. The activity of serum aspartate aminotransferase and alanine aminotransferase was markedly decreased in the DSW-yogurt and N-yogurt groups, and triglyceride level tended to be lower in the DSW-yogurt group compared with that in the control mice. Furthermore, the DSW-yogurt group showed a more significant decrease in the ratio of total cholesterol to high-density lipoprotein-cholesterol than did the N-yogurt group. These findings suggest that DSW supplementation of yogurt can increase its beneficial effects on lipid metabolism.
\end{abstract}

Key words: deep sea water, yogurt, serum parameter, intestinal microbiota

\section{INTRODUCTION}

Deep sea water (DSW) is the term for ocean layers found $200 \mathrm{~m}$ below the surface that are too deep to be reached by sunlight (Nakasone and Akeda, 1999). Deep sea water, comprising most of the water in the oceans on the earth, is rich in nutrients generated by the degradation of marine organisms (Nakagawa et al., 2000). Thus, DSW contains higher concentrations of $\mathrm{Ca}, \mathrm{Mg}$,

Received February 21, 2015.

Accepted May 26, 2015.

${ }^{1}$ Corresponding author: gykim@kangwon.ac.kr
$\mathrm{K}$, vanadium $(\mathrm{V})$, and $\mathrm{Zn}$ than surface water (Hataguchi et al., 2005) and, in recent years, has been widely used in food processing, agriculture, and pharmaceutical and cosmetic industries. Deep sea water, with its unique chemical composition, has been shown to have therapeutic effects not only in the treatment of skin conditions such as atopic eczema/dermatitis syndrome, but also in the prevention of life-threatening diseases, including cancer, diabetes, obesity, hypertension, hypercholesterolemia, and atherosclerosis (Nakagawa et al., 2000; Kimata et al., 2002; Yoshioka et al., 2003; Miyamura et al., 2004; Shon et al., 2008; Hwang et al., 2009).

Some countries, including the United States, Korea, Japan, and Taiwan, have succeeded in using DSW as a natural resource for domestic industries (Nakasone and Akeda, 1999; Liu et al., 2008). Korea has commercialized the use of DSW in areas such as energy production, medicine, cosmetics, aquaculture, agriculture, and food and beverage production. In particular, the food and beverage industry uses DSW to produce salt, soybean sauce, soybean paste, bean curd, kimchi, and potable water. However, DSW has not yet been applied to the production of animal-based food such as milk products.

Yogurt is one of the major foods of probiotics that help in maintaining the healthy status of the intestinal microbiota (Ouwehand et al., 1999). It has been established that yogurt consumption can provide important health benefits, including inhibition of carcinogenesis and mutagenesis, prevention of hypertension, decrease in levels of serum total cholesterol (TC), low density lipoprotein-cholesterol (LDL-C), and triglyceride (TG; Matar et al., 1997; Taranto et al., 2000; Usman and Hosono, 2000; Rodríguez-Figueroa et al., 2010; Ejtahed et al., 2011). Given that mineral intake also improves lipid metabolism and thus reduces the risk of cardiovascular disease (Hines et al., 1985; Kisters et al., 1993; Bakalli et al., 1995; Jenner et al., 2007), the addition of DSW may enhance the health-improving effects of yogurt. However, there is little information on the potential health or nutritional benefits of DSW-supplemented yogurt. Therefore, this study was conducted to estimate 
the effect of DSW-containing yogurt on health-related serum parameters and intestinal microbiota in mice.

\section{MATERIALS AND METHODS}

\section{Reagents and Chemicals}

Aspartate aminotransferase (AST), alanine aminotransferase (ALT), TG, TC, and high-density lipoprotein-cholesterol (HDL-C) were assayed using commercial kits (Asan Pharmaceutical, Seoul, Korea). Phosphate-buffered saline and sodium azide were obtained from Sigma-Aldrich Co. LLC (St. Louis, MO). Plate count agar and de Man, Rogosa, Sharpe agar (MRS) for the cultivation and enumeration of Lactobacillus spp. were purchased from Becton Dickinson (Sparks, MD).

\section{Deep Sea Water}

Experimental DSW was supplied by the Korea Water Resources Corporation (KWRC; Daejeon, Korea). Deep sea water was taken at the depth of $605 \mathrm{~m}$ in the East Sea (between 38.35 and 38.39 latitude and between 128.56 and 128.60 longitude), about $6 \mathrm{~km}$ northeast of the Deep Ocean Water Application Research Center (Goseong, Gangwon-do, Korea) and processed using a reverse osmosis membrane (SU-810, Toray Industries Inc., Tokyo, Honshu, Japan). Detailed information on DSW quality was provided by the KWRC: $\mathrm{pH}=7.6$; total dissolved solids $=51.0 \mathrm{~g} / \mathrm{L}$; electrical conductivity $=78.5 \mathrm{mS} / \mathrm{cm}$; salinity $=53.12 \%$; hardness $=10.3 \mathrm{~g}$ of $\mathrm{CaCO}_{3} / \mathrm{L}$; chloride $=30.84 \mathrm{~g} / \mathrm{L}$. The mineral composition of DSW was as follows: $\mathrm{Cu}, 3.41 \mu \mathrm{g} / \mathrm{L} ; \mathrm{Mn}, 5.84$ $\mu \mathrm{g} / \mathrm{L} ; \mathrm{Zn}, 46.33 \mu \mathrm{g} / \mathrm{L} ; \mathrm{Fe}, 26.25 \mu \mathrm{g} / \mathrm{L}$ (Yoon et al., 2009).

\section{Yogurt Preparation}

We prepared 2 types of yogurts, normal yogurt (Nyogurt) and DSW-containing yogurt (DSW-yogurt). The N-yogurt was manufactured as follows: $70 \%$ fresh market cow milk was mixed with $3 \%$ skim milk powder (calorie, 3,550 kcal $/ \mathrm{kg}$; carbohydrate, $52 \%$; fat, $1 \%$; protein, 35\%; Ca, 1.1\%; Na, 0.6\%; Seoul Dairy Cooperative, Seoul, Korea), $3 \%$ glucose, and $24 \%$ deionized water, sterilized at $95^{\circ} \mathrm{C}$ for $15 \mathrm{~min}$ and cooled to $40^{\circ} \mathrm{C}$. Then, $0.025 \%$ (wt/wt) lactase (Ha-Lactase, Chr. Hansen A/S, Hørsholm, Denmark) and 2\% (wt/wt) starter culture were added; we used salt-resistant lactic acid bacteria (LAB; Lactobacillus pentosus and Pediococcus pentosaceus) in consideration of the salt contained in DSW. The mixture was fermented at $38^{\circ} \mathrm{C}$ for $12 \mathrm{~h}$.
In DSW-yogurt, 10\% DSW instead of 10\% deionized water was used; otherwise, the process was the same. The final products were stored at $4^{\circ} \mathrm{C}$ until use. The $\mathrm{pH}$ value of $\mathrm{N}$-yogurt and DSW-yogurt was measured using a pH meter (SevenEasy pH, Mettler-Toledo AG, Zurich, Switzerland) equipped with an electrode (InLab Expert Pro, Mettler-Toledo AG). Their LAB population was determined by culture in MRS agar containing 0.02\% sodium azide. Both yogurts had same $\mathrm{pH}$ value (4.5) and LAB count $\left(9.1 \log _{10} \mathrm{cfu} / \mathrm{g}\right)$.

\section{In Vivo Experimental Design}

Thirty-six outbred albino female ICR mice (BW of 20 to 26 g) were purchased from Daehan BioLink Co. Ltd. (Eumseong, Korea). For a week, the mice were acclimated to the rearing environment and fed a basal diet (CP, 20.5\%; crude fat, $3.5 \%$; crude fiber, $8 \%$; crude ash, 8\%; Ca, 0.5\%; P, 0.5\%; RodFeed, Daehan BioLink Co. Ltd., Eumseong, Korea). The animals were then assigned to 3 feeding groups of 12 mice each: the control group received water, and the N-yogurt and DSW-yogurt groups received the respective yogurts; all groups were fed a basal diet as well. Mice were reared in a room maintained at $23 \pm 2^{\circ} \mathrm{C}$ and $55 \pm 5 \%$ relative humidity on a 12-h light-dark cycle. At wk 4 or 8,6 mice in each group were fasted for $12 \mathrm{~h}$, anesthetized, and killed; then, blood was collected by cardiac puncture and the small intestines were harvested. Blood was left at room temperature for $30 \mathrm{~min}$ to coagulate. Serum was separated by centrifugation at $890 \times g$ for $30 \mathrm{~min}$.

\section{Analyses of AST and ALT}

The activities of AST (EC 2.6.1.1; L-aspartate: 2-oxoglutarate aminotransferase; glutamic-oxaloacetic transaminase) and ALT (EC 2.6.1.2; L-alanine: 2-oxoglutarate aminotransferase; glutamic-pyruvic transaminase) were analyzed as described by Reitman and Frankel (1957). For the AST assay, $200 \mu \mathrm{L}$ of serum was mixed with $1 \mathrm{~mL}$ of AST substrate reagent (Laspartate and $\alpha$-ketoglutarate) and incubated at $37^{\circ} \mathrm{C}$ for $60 \mathrm{~min}$. Samples for the ALT assay was mixed with substrate reagent (L-alanine and $\alpha$-ketoglutarate) and incubated at $37^{\circ} \mathrm{C}$ for $30 \mathrm{~min}$. Then, $1 \mathrm{~mL}$ of 2,4-dinitrophenylhydrazine was added, and brown-colored complex (hydrazone) was developed after incubation at room temperature for $20 \mathrm{~min}$. The reaction was stopped with $10 \mathrm{~mL}$ of $0.4 \mathrm{~N} \mathrm{NaOH}$ and the absorbance was measured at $505 \mathrm{~nm}$ using a UV-mini-1240 spectrophotometer (Shimadzu Corp., Tokyo, Japan). Deionized water and lithium pyruvate prepared with the same process were used as a blank and standard, 
respectively. The AST (or ALT) activity was calculated as unit of AST (or ALT) in $1 \mathrm{~L}$ of serum using the standard curve of lithium pyruvate.

\section{Measurement of Serum TG}

Serum TG content was determined according to the method of Fossati and Prencipe (1982). Twenty microliters of serum was incubated with $3 \mathrm{~mL}$ of enzyme medium [150 units/mL of lipoprotein lipase, 0.075 units/ $\mathrm{mL}$ of glycerol kinase, 2.22 units $/ \mathrm{mL}$ of $\mathrm{L}$ - $\mathrm{\alpha}$-glycerolphosphate oxidase, and 1,875 units/mL of peroxidase in $\quad 0.427 \% \quad N, N$-bis(2-hydroxyethyl)-2-aminomethane sulfonic acid] at $37^{\circ} \mathrm{C}$ for $10 \mathrm{~min}$. Deionized water and $0.3 \%$ glycerol $(20 \mu \mathrm{L}$ each) incubated with the enzyme medium were used as a blank and standard, respectively. The absorbance was measured at $550 \mathrm{~nm}$ using a UV-2401PC spectrophotometer (Shimadzu Corp.) and TG content was expressed as the amount (mg) of TG in $1 \mathrm{dL}$ of serum according to the formula: (sample absorbance - blank absorbance) $\div$ (standard absorbance - blank absorbance) $\} \times$ standard concentration (300 mg of glycerol/dL).

\section{Measurement of TC}

Serum TC content was determined according to the protocol of Savoldi et al. (1976), wherein $20 \mu \mathrm{L}$ serum was first reacted with $3 \mathrm{~mL}$ of enzyme medium (20.5 units/mL cholesterol esterase and 10.7 units/mL cholesterol oxidase in $45 \mathrm{~m} M \mathrm{NaOH}, 19 \mathrm{~m} M$ phenol, and $100 \mathrm{~m} M$ potassium phosphate) at $37^{\circ} \mathrm{C}$ for $5 \mathrm{~min}$. The absorbance of the sample, blank $(20 \mu \mathrm{L}$ of deionized water), and standard $(20 \mu \mathrm{L}$ of $0.3 \%$ cholesterol) was then measured at $500 \mathrm{~nm}$ and TC content was calculated as the amount (mg) of $\mathrm{TC}$ in $1 \mathrm{dL}$ of serum using the following formula: $\{$ (sample absorbance - blank absorbance $) \div$ (standard absorbance - blank absorbance $)\}$ $\times$ standard concentration (300 mg of cholesterol/dL).

\section{Measurement of HDL-C}

To measure serum HDL-C content, $200 \mu \mathrm{L}$ serum was transferred to a microtube, mixed with $200 \mu \mathrm{L}$ of $0.5 \%$ sodium phosphotungstate- $1 \%$ magnesium chloride, incubated at room temperature for $10 \mathrm{~min}$, and centrifuged at $890 \times g$ for 10 min using a Micro $17 \mathrm{R}+$ centrifuge (Hanil Science Industrial, Incheon, Korea). The supernatant $(100 \mu \mathrm{L})$ was incubated with $3 \mathrm{~mL}$ of enzyme medium (20.5 units/mL cholesterol esterase and 10.7 units $/ \mathrm{mL}$ cholesterol oxidase in $45 \mathrm{mM} \mathrm{NaOH}$, $19 \mathrm{~m} M$ phenol, $100 \mathrm{~m} M$ potassium phosphate) at $37^{\circ} \mathrm{C}$ for $5 \mathrm{~min}$ and the absorbance of the sample, standard
(100 $\mu \mathrm{L}$ of $0.05 \%$ cholesterol), and blank $(100 \mu \mathrm{L}$ of deionized water) was measured at $500 \mathrm{~nm}$. The HDL-C content was calculated as the amount (mg) of HDL-C in $1 \mathrm{dL}$ of serum using the following formula: \{(sample absorbance - blank absorbance) $\div$ (standard absorbance - blank absorbance) $\} \times$ standard concentration $(50 \mathrm{mg}$ cholesterol/dL) $\times$ dilution factor $(2)$.

\section{Quantification of Total Bacteria and LAB}

The contents of the small intestine $(1 \mathrm{~g})$ were mixed with sterile PBS for $60 \mathrm{~s}$, and serially diluted 10-fold. The total bacteria (TB) population was determined by the pour plate technique. Each dilution was placed in an empty plate, covered with melted PCA, and incubated at $37^{\circ} \mathrm{C}$ for $48 \mathrm{~h}$. Then, LAB were counted after incubation in MRS agar containing $0.02 \%$ sodium azide at $32^{\circ} \mathrm{C}$ for $72 \mathrm{~h}$. Colony counts (30 to 300 ) were multiplied by the dilution factor and results were expressed as $\log _{10} \mathrm{cfu} / \mathrm{g}$ intestinal content.

\section{Statistical Analysis}

The data are expressed as the mean \pm standard deviation; differences between group means were tested by ANOVA followed by Duncan's multiple range test. All statistical tests were performed using the SPSS (2011) program; $P<0.05$ was considered statistically significant.

\section{RESULTS AND DISCUSSION}

\section{AST and ALT Activities}

The activities of AST and ALT in blood have been found to be useful biomarkers of chronic liver diseases, including hepatitis, cirrhosis, and fatty liver disease, which may be manifestations of underlying metabolic syndromes such as diabetes mellitus, hyperlipidemia, and porphyria cutanea tarda (Jung et al., 1985; Rosenthal and Haight, 1990). At wk 4 of feeding, the DSWyogurt and N-yogurt groups had significantly $(P<$ 0.05) lower AST activity compared with that in the control mice (Figure 1); however, no statistical difference was found between the 2 yogurt groups. Yogurt also decreased serum ALT activity, which was significantly lower in the N-yogurt group at wk $8(P<0.05)$ and in the DSW-yogurt group at wk 4 and $8(P<0.05)$ of feeding compared with that in the control group; however, we found no significant difference between the yogurt groups (Figure 2). Our findings are consistent with the study of Minelli et al. (2004), who reported that feeding yogurt to rats resulted in decreases in 
$\square$ Control $\square \mathrm{N}-$ Yogurt $\square \mathrm{DSW}-$ Yogurt

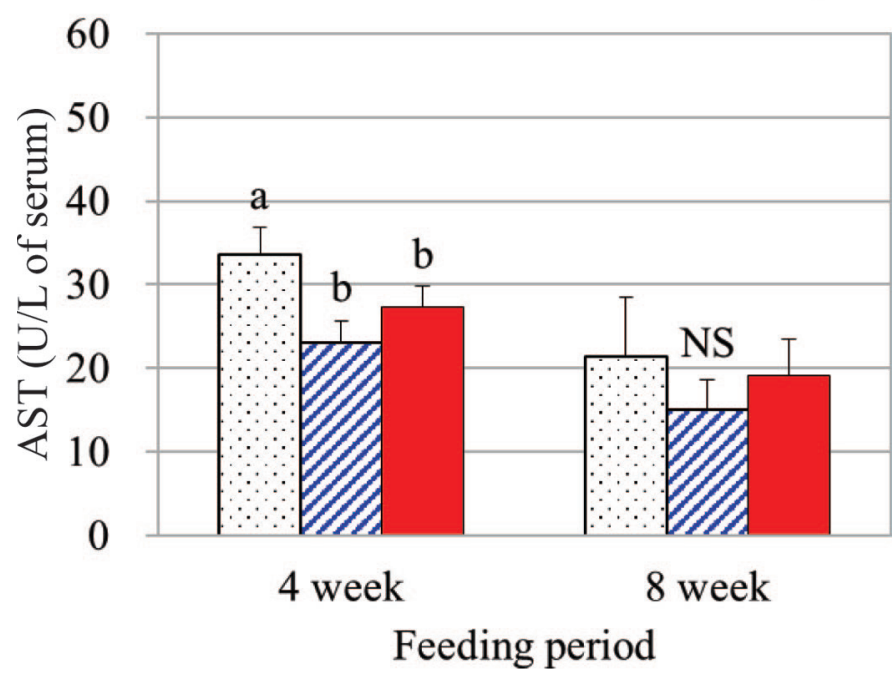

Figure 1. Effect of yogurt containing deep sea water (DSW) on serum aspartate aminotransferase (AST) activity (U/L of serum) in mice. The animals ( $\mathrm{n}=6$ in each group) received water (control), normal yogurt (N-yogurt), or DSW-containing yogurt (DSW-yogurt) together with a basal diet for 4 or 8 wk. The data are presented as means \pm SD. Different letters $(\mathrm{a}, \mathrm{b})$ indicate significant differences among groups $(P<0.05)$. NS $=$ not significant $(P>0.05)$. Color version available online.

serum AST and ALT, whereas Yoshioka et al. (2003) observed that DSW supplementation decreased serum ALT activity in rabbits receiving a diet containing $1 \%$ cholesterol. The effect of DSW could be caused by its microelement components, as evidenced by previous studies showing that in rats and laying hens, dietary supplementation with $\mathrm{Zn}$ and $\mathrm{Cu}$, respectively, resulted in a reduction of serum AST and ALT (Kechrid and Bouzerna, 2004; Güçlü et al., 2008).

\section{TG Content}

Hokanson and Austin (1996) reported that blood TG level is a risk factor for cardiovascular disease independent of HDL-C level. Our results showed that feeding Nyogurt or DSW-yogurt had insignificant effects on TG level in mice (Figure 3). However, in the DSW-yogurt group, we found a tendency for a decreasing serum TG level compared with the control group at both wk 4 and 8 ; in the N-yogurt mice, the TG reduction was observed at wk 8 . These results are consistent with the findings that yogurt supplementation led to a small decrease of serum TG level in rats (Kawase et al., 2000) and that DSW supplementation slightly decreased serum TG in BALB/c mice (Tsuchiya et al., 2002) and rabbits fed a diet containing $0.5 \%$ cholesterol (Sheu et al., 2013). Other studies have shown that dietary mineral caused a reduction of total lipids in tissue, including blood. Feeding Ca to goats reduced lipid content in the aorta (Hines et al., 1985), whereas $\mathrm{Cu}$ intake by steers decreased subcutaneous fat and saturated fatty acids in muscle (Engle et al., 2000). It has also been reported that dietary $\mathrm{Mg}$ supplementation decreased serum TG level in patients with hyperlipidemia (Kisters et al., 1993).

\section{Cholesterol Content}

Blood TC content is a biomarker that can predict the risk of ischemic heart disease, and it has been demonstrated that the ratio of TC to HDL-C has more predictive value than that of LDL-C to HDL-C (Lemieux et al., 2001). As shown in Figure 4, both N-yogurt and DSW-yogurt had a significant effect on serum cholesterol level in mice. Thus, DSW-yogurt decreased TC level and TC to HDL-C ratio and increased HDL-C level both at wk 4 and 8 compared with that in the control $(P<0.05)$. Furthermore, DSW-yogurt caused a more significant reduction of serum TC level at wk $8(P<0.05)$ and TC to HDL-C ratio at wk 4 and $8(P<0.05)$ compared with N-yogurt. Our findings are in agreement with previous studies showing the reduction of serum TC and LDL-C levels by yogurt in mice (Akalin et al., 1997) and by DSW in $0.25 \%$ cholesterol-fed rabbits, which also demonstrated an

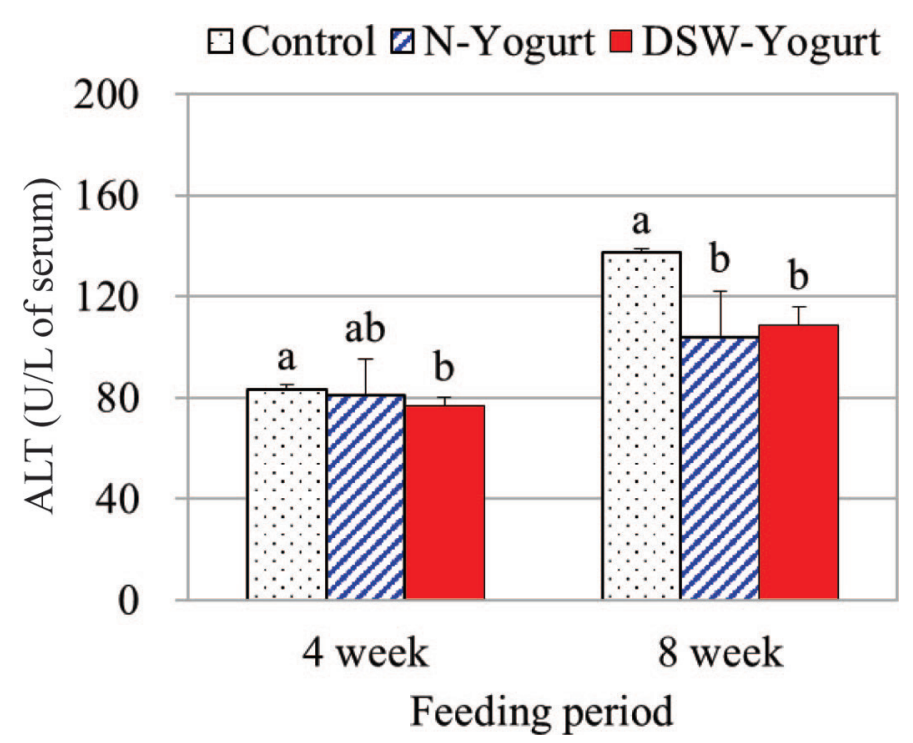

Figure 2. Effect of yogurt containing deep sea water (DSW) on serum alanine aminotransferase (ALT) activity (U/L of serum) in mice. The animals ( $\mathrm{n}=6$ in each group) received water (control), normal yogurt (N-yogurt), or DSW-containing yogurt (DSW-yogurt) together with a basal diet for 4 or $8 \mathrm{wk}$. The data are presented as means $\pm \mathrm{SD}$. Different letters $(\mathrm{a}, \mathrm{b})$ indicate significant differences among groups $(P$ $<0.05$ ). Color version available online. 


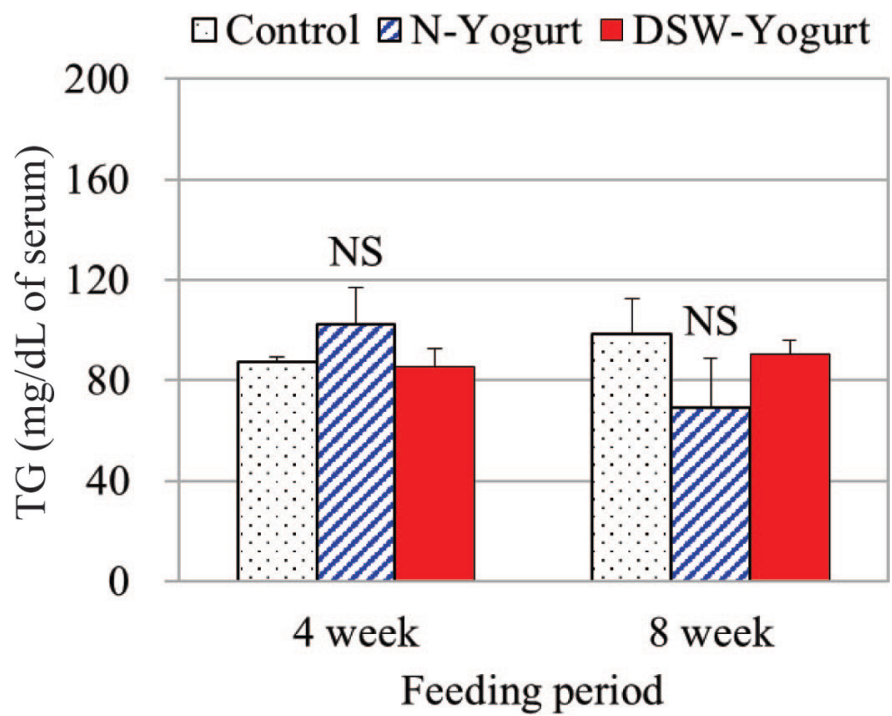

Figure 3. Effect of yogurt containing deep sea water (DSW) on serum triglyceride (TG) level $(\mathrm{mg} / \mathrm{dL}$ of serum) in mice. The animals (n $=6$ in each group) received water (control), normal yogurt (N-yogurt), or DSW-containing yogurt (DSW-yogurt) together with a basal diet for 4 or $8 \mathrm{wk}$. The data are presented as means $\pm \mathrm{SD}$. NS $=$ not significant $(P>0.05)$. Color version available online.

increase in plasma HDL-C (Miyamura et al., 2004). Moreover, DSW decreased plasma TC level in a mouse model of type II diabetes (Hwang et al., 2009). Several studies have demonstrated the effect of dietary minerals on cholesterol metabolism in mammals. Jenner et al. (2007) reported that dietary $\mathrm{Zn}$ decreased TC content in the aorta of $1 \%$ cholesterol-fed rabbits, and Bakalli et al. (1995) observed that $\mathrm{Cu}$ supplementation sharply reduced TC in plasma and muscle of broilers. In addition, $\mathrm{Mg}$ consumption is thought to be beneficial for the mitigation of hyperlipidemia in patients with diabetes mellitus (Corica et al., 1994).

\section{Microbial Population}

Total bacteria and LAB counts in the small intestine were higher in mice fed DSW-yogurt and N-yogurt than in control animals at wk $4(P<0.05$; Figure 5$)$. We detected no difference between yogurt groups at either wk 4 or wk 8. Feeding DSW did not negatively affect LAB population in starter cultures or in the small intestine because the majority of LAB can survive in relatively high salinity, such as $2.5 \% \mathrm{NaCl}$ (Orla-Jensen, 1919) and the salinity of DSW-yogurt was only about $5.31 \%$ $(0.53 \%)$. Yogurt is a good source of probiotic bacteria, which are used as food supplements because of their beneficial effects on human health. Lactic acid bacteria help in maintaining the balance of intestinal microbiota by producing antimicrobial agents (e.g., bacteriocins)
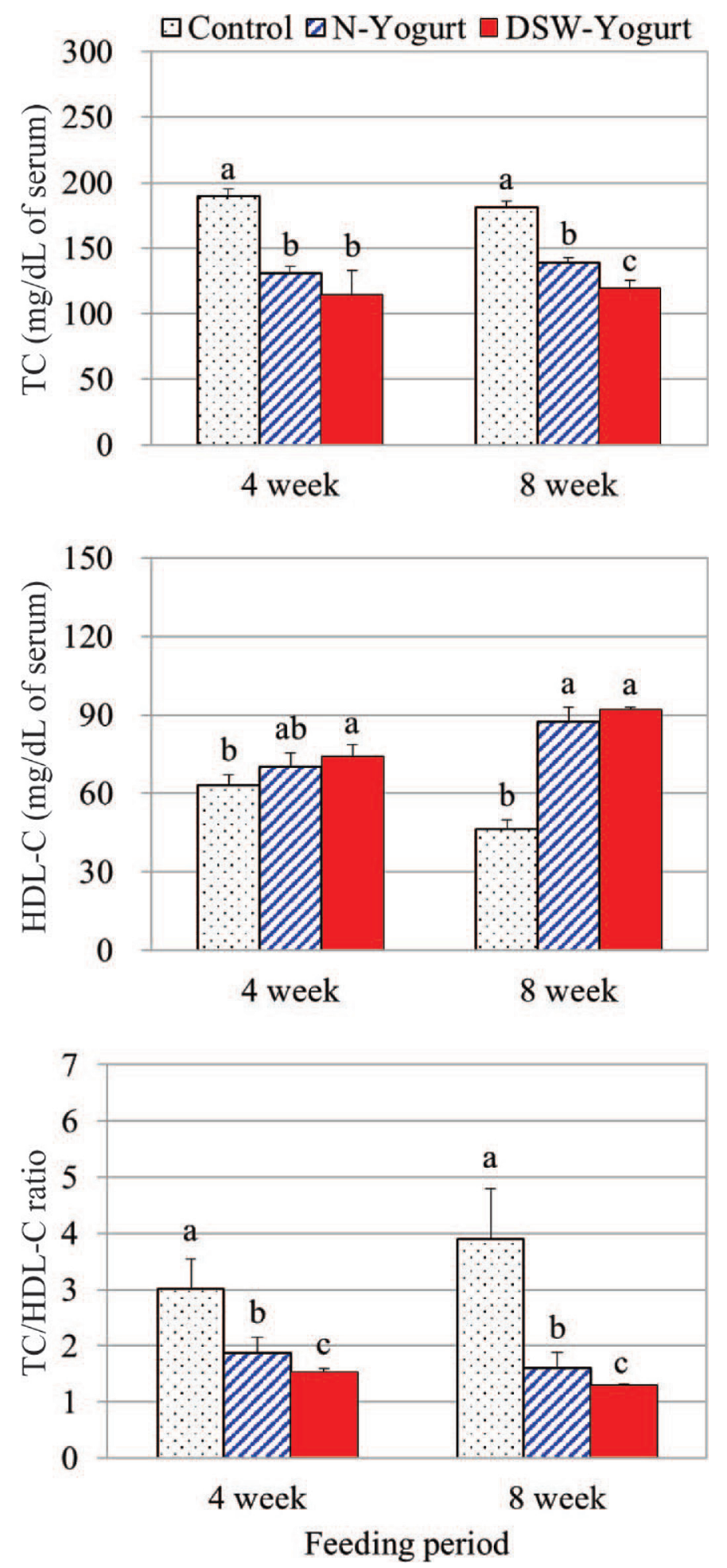

Figure 4. Effect of yogurt containing deep sea water (DSW) on serum cholesterol level $(\mathrm{mg} / \mathrm{dL}$ of serum) in mice. The animals $(\mathrm{n}=$ 6 in each group) received water (control), normal yogurt (N-yogurt), or DSW-containing yogurt (DSW-yogurt) together with a basal diet for 4 or $8 \mathrm{wk}$. The data are presented as means $\pm \mathrm{SD}$. Different letters $(\mathrm{a}-\mathrm{c})$ indicate significant differences among groups $(P<0.05)$. TC $=$ total cholesterol; HDL-C $=$ high density lipoprotein-cholesterol. Color version available online. 

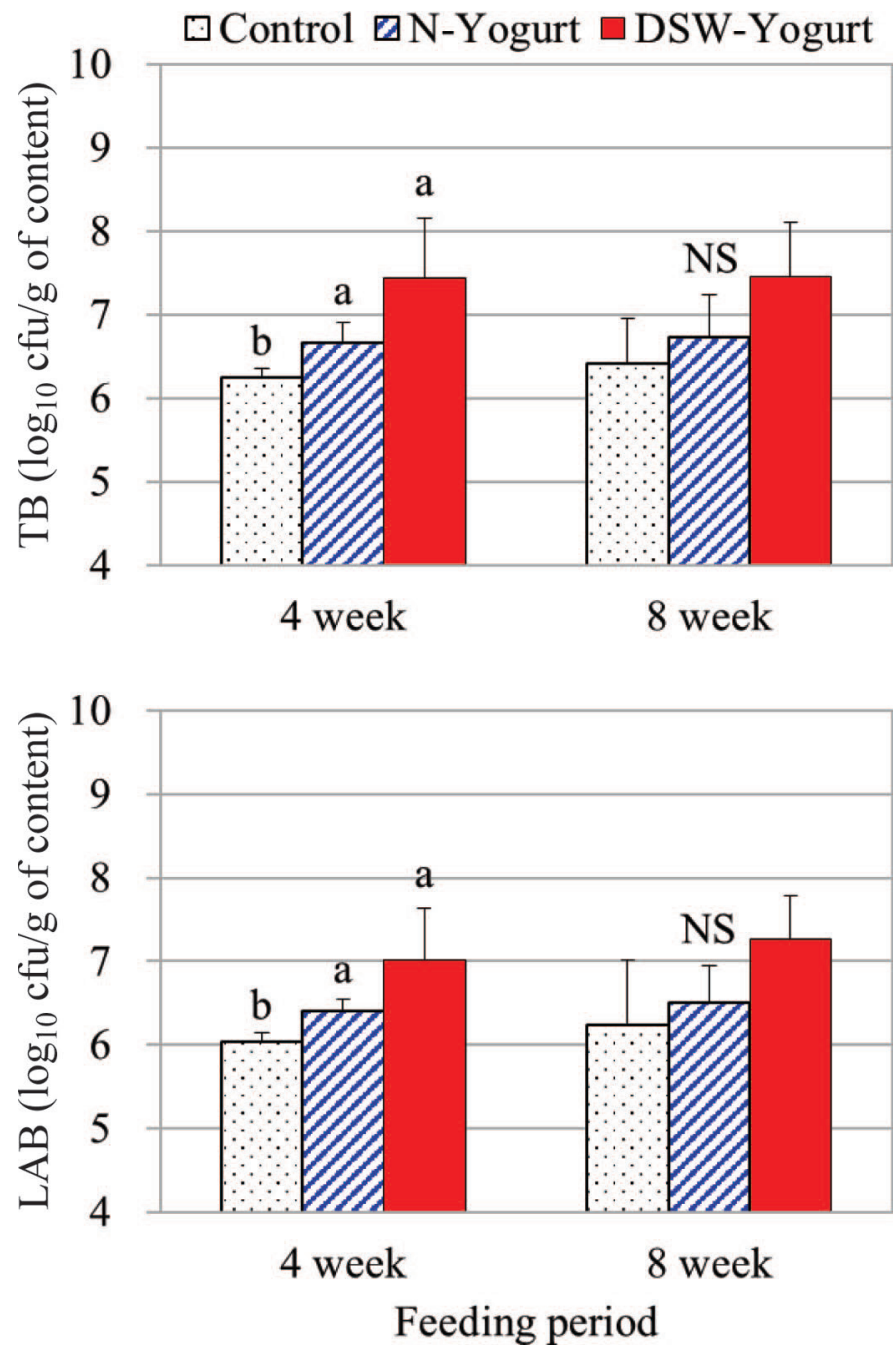

Figure 5. Effect of yogurt containing deep sea water (DSW) on microbial population $\left(\log _{10} \mathrm{cfu} / \mathrm{g}\right.$ of content) in the small intestine. The animals ( $\mathrm{n}=6$ in each group) received water (control), norma yogurt (N-yogurt), or DSW-containing yogurt (DSW-yogurt) together with a basal diet for 4 or $8 \mathrm{wk}$. The data are presented as means $\pm \mathrm{SD}$. Different letters $(\mathrm{a}, \mathrm{b})$ indicate significant differences among groups $(P$ $<0.05) . \mathrm{NS}=$ not significant $(P>0.05) . \mathrm{TB}=$ total bacteria; $\mathrm{LAB}=$ lactic acid bacteria. Color version available online.

and inhibiting pathogenic bacteria, stimulate immune system, and play a role in the prevention of diseases such as atopic dermatitis, diabetes, obesity, and cancer (Tannock, 1998; Ouwehand et al., 1999; Taranto et al., 2000). Lactobacillus pentosus and Pediococcus pentosaceus, starter cultures in our yogurt preparations, have long been used for food fermentation and are recommended as practical probiotics for humans (EFSA, 2007; Gaggìa et al., 2010). The intake of LAB-fermented dairy products significantly increases LAB colonization of the gastrointestinal tract; however, these probiotics may not persist (Link-Amster et al., 1994; Spanhaak et al., 1998; Ouwehand et al., 1999).

\section{CONCLUSIONS}

Yogurt supplementation improved metabolic syndrome-related serum parameters and increased intestinal LAB population in mice. Deep sea water containing bioactive microelements enhanced the beneficial effects of yogurt on lipid metabolism. Further research is needed to investigate the effects of DSW-yogurt on human health.

\section{ACKNOWLEDGMENTS}

This study was supported by the Korea Water Resources Corporation (Daejeon, Korea).

\section{REFERENCES}

Akalin, A. S., S. Gönç, and S. Düzel. 1997. Influence of yogurt and acidophilus yogurt on serum cholesterol levels in mice. J. Dairy Sci. 80:2721-2725.

Bakalli, R. I., G. M. Pesti, W. L. Ragland, and V. Konjufca. 1995 Dietary copper in excess of nutritional requirement reduces plasma and breast muscle cholesterol of chickens. Poult. Sci. 74:360-365.

Corica, F., A. Allegra, A. Di Benedetto, M. S. Giacobbe, G. Romano, D. Cucinotta, M. Buemi, and D. Ceruso. 1994. Effects of oral magnesium supplementation on plasma lipid concentrations in patients with non-insulin-dependent diabetes mellitus. Magnes. Res. $7: 43-47$.

EFSA. 2007. European food safety authority. Introduction of a qualified preconsumption of safety (QPS) approach for assessment of selected microorganisms referred to EFSA Opinion of the Scientific Committee (Question No EFSA-Q-2005-293) adopted on 19 November 2007. EFSA J. 587:1-16.

Ejtahed, H. S., J. Mohtadi-Nia, A. Homayouni-Rad, M. Niafar, M. Asghari-Jafarabadi, V. Mofid, and A. Akbarian-Moghari. 2011. Effect of probiotic yogurt containing Lactobacillus acidophilus and Bifidobacterium lactis on lipid profile in individuals with type 2 diabetes mellitus. J. Dairy Sci. 94:3288-3294.

Engle, T. E., J. W. Spears, T. A. Armstrong, C. L. Wright, and J. Odle. 2000. Effects of dietary copper source and concentration on carcass characteristics and lipid and cholesterol metabolism in growing and finishing steers. J. Anim. Sci. 78:1053-1059.

Fossati, P., and L. Prencipe. 1982. Serum triglycerides determined colorimetrically with an enzyme that produces hydrogen peroxide. Clin. Chem. 28:2077-2080.

Gaggìa, F., P. Mattarelli, and B. Biavati. 2010. Probiotics and prebiotics in animal feeding for safe food production. Int. J. Food Microbiol. 141:S15-S28.

Güçlü, B. K., K. Kara, L. Beyaz, F. Uyanik, M. Eren, and A. Atasever. 2008. Influence of dietary copper proteinate on performance, selected biochemical parameters, lipid peroxidation, liver, and egg copper content in laying hens. Biol. Trace Elem. Res. 125:160169.

Hataguchi, Y., H. Tai, and H. Kimata. 2005. Drinking deep-sea water restores mineral imbalance in atopic eczema/dermatitis syndrome. Eur. J. Clin. Nutr. 59:1093-1096.

Hines, T. G., N. L. Jacobson, D. C. Beitz, and E. T. Littledike. 1985. Dietary calcium and vitamin D: risk factors in the development of atherosclerosis in young goats. J. Nutr. 115:167-178.

Hokanson, J. E., and M. A. Austin. 1996. Plasma triglyceride level is a risk factor for cardiovascular disease independent of high-density lipoprotein cholesterol level: A metaanalysis of population-based prospective studies. J. Cardiovasc. Risk 3:213-219.

Hwang, H. S., H. A. Kim, S. H. Lee, and J. W. Yun. 2009. Anti-obesity and antidiabetic effects of deep sea water on ob/ob mice. Mar. Biotechnol. (NY) 11:531-539. 
Jenner, A., M. Ren, R. Rajendran, P. Ning, B. T. K. Huat, F. Watt, and B. Halliwell. 2007. Zinc supplementation inhibits lipid peroxidation and the development of atherosclerosis in rabbits fed a high cholesterol diet. Free Radic. Biol. Med. 42:559-566.

Jung, K., M. Pergande, R. Rej, G. Schreiber, and W. Schimmelpfennig. 1985. Mitochondrial enzymes in human serum: Comparative determinations of glutamate dehydrogenase and mitochondrial aspartate aminotransferase in healthy persons and patients with chronic diseases. Clin. Chem. 31:239-243.

Kawase, M., H. Hashimoto, M. Hosoda, H. Morita, and A. Hosono. 2000. Effect of administration of fermented milk containing whey protein concentrate to rats and healthy men on serum lipids and blood pressure. J. Dairy Sci. 83:255-263.

Kechrid, Z., and N. Bouzerna. 2004. Effect of zinc deficiency and experimental diabetes on glutamate oxaloacetic, glutamate pyruvate aminotransferases and alkaline phosphatase activities in rats. Int. J. Diabetes Metab. 11:14-18.

Kimata, H., H. Tai, K. Nakagawa, Y. Yokoyama, H. Nakajima, and Y. Ikeqami. 2002. Improvement of skin symptoms and mineral imbalance by drinking deep-sea water in patients with atopic eczema/ dermatitis syndrome (AEDS). Acta Medica (Hradec Kralove) 45:83-84.

Kisters, K., C. Spieker, M. Tepel, and W. Zidek. 1993. New data about the effects of oral physiological magnesium supplementation on several cardiovascular risk factors (lipids and blood pressure). Magnes. Res. 6:355-360.

Lemieux, I., B. Lamarche, C. Couillard, A. Pascot, B. Cantin, J. Bergeron, G. R. Dagenais, and J. P. Després. 2001. Total cholesterol/HDL cholesterol ratio vs LDL cholesterol/HDL cholesterol ratio as indices of ischemic heart disease risk in men: The Quebec cardiovascular study. Arch. Intern. Med. 161:2685-2692.

Link-Amster, H., F. Rochat, K. Y. Saudan, O. Mignot, and J. M. Aeschlimann. 1994. Modulation of a specific humoral immune response and changes in intestinal flora mediated through fermented milk intake. FEMS Immunol. Med. Microbiol. 10:55-63.

Liu, T. K., H. H. Hwung, J. L. Yu, and R. C. Kao. 2008. Managing deep ocean water development in Taiwan: Experiences and future challenges. Ocean Coast. Manage. 51:126-140.

Matar, C., S. S. Nadathur, A. T. Bakalinsky, and J. Goulet. 1997. Antimutagenic effects of milk fermented by Lactobacillus helveticus L89 and a protease-deficient derivative. J. Dairy Sci. 80:19651970.

Minelli, E. B., A. Benini, M. Marzotto, A. Sbarbati, O. Ruzzenente, R. Ferrario, H. Hendriks, and F. Dellaglio. 2004. Assessment of novel probiotic Lactobacillus casei strains for the production of functional dairy foods. Int. Dairy J. 14:723-736.

Miyamura, M., S. Yoshioka, A. Hamada, D. Takuma, J. Yokota, M. Kusunose, S. Kyotani, H. Kawakita, K. Odani, Y. Tsutsu, and Y. Nishioka. 2004. Difference between deep seawater and surface seawater in the preventive effect of atherosclerosis. Biol. Pharm. Bull. 27:1784-1787.

Nakagawa, K., Y. Yokoyama, H. Nakajima, and Y. Ikegami. 2000. Application of minerals in deep seawater. Deep Ocean Water Res. $1: 1-4$.

Nakasone, T., and S. Akeda. 1999. The application of deep sea water in Japan. Proceedings of the 28th United States-Japan Coopera- tive Program in Natural Resources Aquaculture Panel Symposium, Kihei, Hawaii.

Orla-Jensen, S. 1919. The Lactic Acid Bacteria. Andre Fred Høst \& Son, Copenhagen, Denmark.

Ouwehand, A. C., P. V. Kirjavainen, C. Shortt, and S. Salminen. 1999. Probiotics: Mechanisms and established effects. Int. Dairy J. 9:43-52.

Reitman, S., and S. A. Frankel. 1957. Colorimetric method for the determination of serum glutamic oxaloacetic and glutamic pyruvic transaminases. Am. J. Clin. Pathol. 28:56-63.

Rodríguez-Figueroa, J. C., R. Reyes-Díaz, A. F. González-Córdova, R. Troncoso-Rojas, I. Vargas-Arispuro, and B. Vallejo-Cordoba. 2010. Angiotensin-converting enzyme inhibitory activity of milk fermented by wild and industrial Lactobacillus lactis strains. J. Dairy Sci. 93:5032-5038.

Rosenthal, P., and M. Haight. 1990. Aminotransferase as a prognostic index in infants with liver disease. Clin. Chem. 36:346-348.

Savoldi, R. B. D. Prandini, and C. Donisi. 1976. Enzymatic determination of total serum cholesterol by 4-aminophenazone-phenol: manual and automatic method. Quad. Sclavo Diagn. 12:238-247.

Sheu, M. J., P. Y. Chou, W. H. Lin, C. H. Pan, Y. C. Chein, Y. L. Chung, F. C. Liu, and C. H. Wu. 2013. Deep sea water modulates blood pressure and exhibits hypolipidemic effects via the AMPKACC pathway: An in vivo study. Mar. Drugs 11:2183-2202.

Shon, Y. H., M. K. Kim, J. S. Jang, E. J. Jung, and K. S. Nam. 2008. Effect of deep sea water on phase I, phase II and ornithine decarboxylase. J. Life Sci. 18:381-386.

Spanhaak, S., R. Havenaar, and G. Schaafsma. 1998. The effect of consumption of milk fermented by Lactobacillus casei strain Shirota on the intestinal microflora and immune parameters in humans. Eur. J. Clin. Nutr. 52:899-907.

SPSS. 2011. PASW Statistics 21. Statistical Package for the Social Sciences Inc., Chicago, IL.

Tannock, G. W. 1998. Studies of the intestinal microflora: A prerequisite for the development of probiotics. Int. Dairy J. 8:527-533.

Taranto, M. P., M. Medici, G. Perdigon, A. P. Ruiz Holgado, and G. F. Valdez. 2000. Effect of Lactobacillus reuteri on the prevention of hypercholesterolemia in mice. J. Dairy Sci. 83:401-403.

Tsuchiya, Y., K. Nakamura, H. Sekikawa, H. Kawamura, K. Miyanishi, T. Ishizu, and M. Yamamoto. 2002. Subacute effects of deepsea water from the Japan Sea on blood examination values in mice. Environ. Health Prev. Med. 7:189-192

Usman, and A. Hosono. 2000. Effect of administration of Lactobacillus gasseri on serum lipids and fecal steroids in hypercholesterolemic rats. J. Dairy Sci. 83:1705-1711.

Yoon, B. S., H. C. Kim, Y. Y. Kim, and S. T. Lee. 2009. Development of the pretreatment methods for analysis of trace heavy metals in seawater. J. Korean Soc. Environ. Anal. 12:151-158.

Yoshioka, S., A. Hamada, T. Cui, J. Yokota, S. Yamamoto, M. Kusunose, M. Miyamura, S. Kyotani, R. Kaneda, Y. Tsutsui, K. Odani, I. Odani, and Y. Nishioka. 2003. Pharmacological activity of deepsea water: Examination of hyperlipemia prevention and medical treatment effect. Biol. Pharm. Bull. 26:1552-1559. 